\title{
ATIVIDADE, DESENGAJAMENTO, MODERNIZAÇÃO: teorias sociológicas clássicas sobre o envelhecimento ${ }^{1}$
}

\author{
Johannes Doll ${ }^{2}$ \\ Ângela Gomes ${ }^{3}$ \\ Leonéia Hollerweger ${ }^{4}$ \\ Rodrigo Monteiro Pecoits ${ }^{5}$ \\ Sionara Tamanini de Almeida ${ }^{6}$
}

\section{Resumo}

A Gerontologia é um campo abrangente que integra várias disciplinas. Além de teorias psicológicas, foram principalmente as grandes teorias sociológicas dos anos 1940 a 1980 que impulsionaram a pesquisa gerontológica internacional. Apesar de históricas, estas teorias influenciam até hoje a pesquisa e, principalmente, o trabalho prático com pessoas idosas. $\mathrm{O}$ artigo apresenta e discute o desenvolvimento de três teorias sociológicas do envelhecimento: a teoria da atividade, a teoria do desengajamento e a teoria da modernização.

Palavras-chave: Envelhecimento. Teorias do Envelhecimento. Gerontologia.

\section{Introdução}

Estudos e pesquisas sobre o envelhecimento aumentaram no Brasil significativamente a partir da década de 80 (PRADO; SAYD, 2004), apesar de não significar necessariamente uma constituição da Gerontolo-

\footnotetext{
${ }^{1}$ Este artigo foi elaborado no contexto da disciplina Prática de Pesquisa: construção de trajetórias sócio-profissionais do Programa de Pós-Graduação em Educação da Universidade Federal do Rio Grande do Sul (UFRGS). Desta forma participaram, além dos autores: Jorge Ribeiro (professor da Disciplina), Carolina Carrion Mendes Ribeiro, Cidriana Teresa Parenza, Kátia Regina Pereira Aniceto, Margareth Fadanelli Simionato, Melissa Pasqual Petenon, Rafael Denes Arruda, Teresinha Backes Piccinini.

${ }^{2}$ Pedagogo. Especialista em Gerontologia pela Universidade de Heidelberg (Alemanha). Mestre em Educação pela UFRGS. Doutor em Filosofia pela Universidade de Koblenz Landau (Alemanha). Professor de graduação e Pós-graduação da UFRGS. E-mail: johannes.doll@ufrgs.br

${ }^{3}$ Licenciatura Plena em Educação Física pela Universidade do Vale dos Sinos (UNISINOS). Especialista em Fisiologia do Exercício pela UFRGS e PROEJA UFRGS. Mestranda em Educação pela UFRGS. E-mail: angel.gomes@pop.com.br

${ }^{4}$ Graduanda em Pedagogia pela UFRGS. Bolsista do Programa Institucional de Bolsa de Iniciação Científica (PIBIC). E-mail: leoneiah@yahoo.com.br

${ }^{5}$ Enfermeiro UFRGS. Mestrando em Educação pela UFRGS. E-mail: rodrigo_pecoits@hotmail.com

${ }^{6}$ Fisioterapeuta da Rede Metodista de Educação do Sul (IPA). Licenciatura Plena em Educação Física UFRGS. Mestranda em Educação UFRGS. Bolsista Capes. E-mail: sionara@cpovo.net
} 
gia como um campo científico demarcado (PRADO; SAYD, 2006). As razões para a dificuldade de se constituir como uma ciência reconhecida vem do seu caráter interdisciplinar, o que dificulta a constituição de uma base teórica consistente e precisa (DOLL, 2006). Em nível internacional, a discussão sobre o campo científico da Gerontologia existe há mais tempo (ACHENBAUM, 1995). Nesta discussão, a Gerontologia foi considerada um campo científico com muitos dados, mas pouco fundamentado e estruturado por teorias (BENGTSON; RICE; JOHNSON, 1999).

Por isso, pode ser uma idéia interessante, na situação atual da gerontologia no Brasil, valorizar o conhecimento de teorias gerontológicas. Pois, além de estruturar e fundamentar dados empíricos, teorias também podem iniciar pesquisas e estudos. Desta forma, teorias não são simplesmente comprovadas ou reprovadas, verdadeiras ou falsas, como aponta uma epistemologia positivista, mas teorias podem ser produtivas para o conhecimento científico. Como Popper (1974) destaca, frente à impossibilidade de comprovar definitivamente uma teoria científica, o cientista deveria trabalhar no sentido de tentar derrubar uma determinada teoria. Somente quando uma teoria resistiu a várias tentativas de reprovação, ela pode ser chamada de "bem corroborada" (POPPER, 1974, p. 303). Neste sentido, a tentativa de derrubar uma teoria pode ajudar a diferenciar esta mesma teoria e desenvolver novas teorias. Foi exatamente este processo que aconteceu no desenvolvimento das primeiras teorias especificamente gerontológicas durante a segunda metade do século XX: a teoria do desengajamento e a teoria da atividade. Principalmente a teoria do desengajamento provocou a comunidade gerontológica da época, levando a estudos empíricos, pesquisas comparativas internacionais e reformulações e diferenciações das teorias propostas. Menos polêmica, mas também uma das primeiras teorias sociológicas específicas sobre o envelhecimento, é a teoria da modernização, cuja origem remete ao ano 1945, mas chega a ser formulada somente em 1972 e 1986 (COWGILL, 1986).

No Brasil, o acesso a essas discussões e aos detalhes dessas teorias é dificultado, não somente por haver poucas publicações mais detalhadas sobre este processo em língua portuguesa, mas também pela dificuldade do acesso aos textos originais, exceto Siqueira (2001; 2002). Por um lado, essas teorias da primeira geração (MARSHALL, 1999) constituem até hoje um dos fundamentos do saber teórico gerontológico (WAHL; HEYL, 2004). Por outro lado, elas entraram, muitas vezes de forma reduzida e 
indiferenciada, no senso comum do trabalho prático com pessoas idosas, bem como nas políticas públicas ${ }^{7}$. Frente a isso, o presente artigo apresenta e discute o surgimento e desenvolvimento de três grandes teorias sociológicas que se referem especificamente ao envelhecimento: a teoria da atividade, a teoria do desengajamento e a teoria da modernização ${ }^{8}$.

\section{Teoria da Atividade}

A teoria da atividade desenvolveu-se no final da década de 40 e se constituiu principalmente em dois diferentes momentos. O primeiro iniciou com Havighurst, publicando em 1953, o livro Developmental Tasks and Education (SCHROOTS, 1996; LEHR, 2000), no qual propunha o conceito de tarefas desenvolvimentais ${ }^{9}$ na perspectiva life span. Tais tarefas surgem na vida das pessoas em determinados períodos. Caso sua realização seja feita com sucesso, o indivíduo terá felicidade e êxito em tarefas posteriores, mas caso a pessoa fracasse, lhe restará a infelicidade e a reprovação pela sociedade. Todas essas tarefas possuem bases biológicas (maturação física), psicológicas (aspirações e valores) e culturais (expectativas da sociedade). Ainda, no mesmo livro, Havighurst (SCHROOTS, 1996; LEHR, 2000) descreveu seis estágios desenvolvimentais ou períodos de idade, cada qual com tarefas próprias. Essa organização do conceito de tarefas desenvolvimentais relacionadas à idade foi nomeada mais tarde de teoria da atividade em oposição à teoria do desengajamento (SCHROOTS, 1996; LEHR, 2000).

$\mathrm{Na}$ década de 60, o mesmo autor desenvolveu um conceito implícito à teoria da atividade: o envelhecimento bem sucedido (successful aging). O conceito aborda as condições de vida individual e social dos idosos. No artigo publicado por Havighurst (1961), há a referência de que o envelhecimento bem sucedido pode ser sustentado por duas diferentes teorias que se contrapõem: a teoria da atividade e a teoria do desengajamento. Em síntese, a teoria da atividade parte do pressuposto de que

7 A análise da constituição do discurso gerontológico não é o foco deste artigo. A respeito disso, veja, por exemplo, Moody (1976), Debert (1999), Groisman (2002) e Neri (2006).

8 Para uma estruturação das diferentes teorias gerontológicas, veja, por exemplo, Marshall (1999), Siqueira (2002) e Wahl e Heyl (2004).

9 A psicologia do desenvolvimento começou, nesta época, a estender sua perspectiva além da infância e juventude. Uma das formas para discutir o desenvolvimento durante a vida inteira (life span) foi a partir de crises que deveriam ser resolvidas para possibilitar uma continuação do desenvolvimento e que constituem, desta forma, tarefas desenvolvimentais. O modelo mais conhecido deste tipo é o de Erikson (1998).

Estud. interdiscip. envelhec., Porto Alegre, v. 12, p. 7-33, 2007. 
o envelhecimento bem sucedido significaria a manutenção, pelo maior tempo possível, das atividades iniciadas na meia-idade, e estas, quando necessário, seriam substituídas. Além disso, Havighurst (1961) destaca a importância da imagem social da velhice na sociedade, da satisfação dos idosos com suas atividades e do contentamento com suas vidas. Já a teoria do desengajamento aponta como sucesso quando as pessoas naturalmente se afastam das atividades sociais até mesmo por um desejo pessoal (HAVIGHURST, 1961).

Havighurst $(1961 ; 1968)$ usou diferentes estudos como base empírica para a teoria da atividade e do envelhecimento bem sucedido, entre estes, também, o Estudo do Kansas City da vida adulta, em que 279 pessoas entre homens e mulheres (idades entre 50-90 anos) foram avaliados no período compreendido entre os anos de 1955 a 1962. Curiosamente, trata-se do mesmo estudo que fundamentou a teoria do desengajamento. $\mathrm{Na}$ análise de Havighurst (1968), com o estudo, percebeu-se que nenhuma das duas teorias explicava o fenômeno do envelhecimento bem sucedido completamente. Entretanto, destacou-se a importância da influência da personalidade entre os aspectos da atividade e da satisfação de vida nas pessoas (HAVIGHURST, 1968; CUMMING; HENRY, 1961).

Dessa forma, a relação entre o nível de atividade e da satisfação de vida seria influenciada também pela personalidade. De fato, os dados da Kansas City Study ${ }^{10}$ apontam para o fator da personalidade como principal dimensão para descrever os estilos de envelhecimento e permitem uma previsão da relação entre nível de atividade e satisfação de vida.

O segundo momento de construção da teoria da atividade foi realizado a partir do estudo de Lemon, Bengtson e Peterson (1972), no qual os autores cuidadosamente aplicaram uma pesquisa que sistematizou a teoria da atividade do envelhecimento (BEARON, 1996; HAVIGHURST, 1968).

Através da sistematização da teoria, foram desenvolvidos conceitos centrais, tais como atividade, suporte de papéis, autoconceito, mudanças de papéis e satisfação de vida; além de discutir a relação entre eles. A definição de atividade, um dentre os vários conceitos, é colocada a seguir:

Qualquer ação regular que possui uma rotina física ou pessoal instituída. O presente estudo envolve a distin-

\footnotetext{
${ }^{10}$ A Kansas City Study of Adult Life foi uma pesquisa, iniciada em 1955 pela Universidade de Chicago, na qual foram entrevistados adultos de todas as faixas etárias (LEHR, 2000).
} 
ção entre três tipos de atividade: (1) atividade informal inclui relações sociais com parentes, amigos e vizinhos; (2) atividade formal, que aborda a participação em organizações formais, tais como associações e sociedades e (3) atividades solitárias que inclui as atividades como assistir televisão, leituras ou hobbies de natureza solitária (LEMON; BENGTSON; PETERSON, 1972, p. 513, tradução Johannes Doll).

Teoremas foram deduzidos a partir dos conceitos relacionando a atividade social e a satisfação de vida, além da elaboração de hipóteses que associavam os três diferentes tipos de atividades à satisfação de vida. Os resultados da pesquisa de Lemon, Bengtson e Peterson (1972) trouxeram limitadas conclusões e contribuições para o avanço da teoria da atividade em função dos tipos de dados analisados, ou seja, dados secundários que não foram coletados especificamente para testar os avanços da teoria. Desta forma, das sete hipóteses testadas, somente duas receberam suporte:

a) as atividades informais, especialmente realizadas com amigos, possuem uma ligação direta com a satisfação de vida;

b) as atividades informais estão mais fortemente ligadas à satisfação de vida do que as atividades formais.

Entretanto, posteriormente, a pesquisa foi replicada por Longino e Kart (1982) cujos achados contribuíram positivamente para a teoria, pois esta concluiu uma forte associação entre as atividades informais e a satisfação de vida dos pesquisados nas três diferentes comunidades analisadas.

Além disso, a teoria da atividade foi originalmente elaborada por meio de bases da pesquisa americana e testada principalmente nos Estados Unidos. Mas com o passar do tempo, novos estudos surgiram, e foram investigados outros contextos, como por exemplo, o inglês (KNAPP, 1977) e o contexto europeu em geral (LEHR, 2000).

Dentre os autores que abordam a teoria da atividade, McClelland (1982) realizou trabalhos buscando ampliar a teoria, explicando a adaptação ao processo de envelhecimento como uma integração com a teoria da subcultura do envelhecimento, já afirmada por Arnold Rose nos anos 60. Nessa perspectiva, o conceito da autoconcepção teria um papel importante no entendimento da atividade social, na adequação social e em outros prognósticos da satisfação de vida necessária ao envelhecimento bem sucedido (MCCLELLAND, 1982). 
Neste modelo ocorre a comunicação entre a teoria da atividade e a teoria da subcultura do envelhecimento, em que ambas aproximam-se fazendo a integração social em aspectos objetivos e subjetivos dos sujeitos no processo de envelhecimento. De acordo com o autor, ambas as perspectivas assumem a influência de fatores sociodemográficos, como a educação e a saúde, sendo a maior diferença entre elas, a ênfase em conceitos distintos. "Para a teoria da atividade, o foco está na satisfação de vida, ao passo que a da subcultura do envelhecimento dá maior atenção ao autoconceito." (MCCLELLAND, 1982, p. 724).

O estudo realizado pelo autor enfatiza que a satisfação de vida e o autoconceito estariam relacionados com o processo de envelhecimento bem sucedido, pois o indivíduo que possui uma inadequada concepção de si mesmo pode ter muitas dificuldades para sentir-se satisfeito com a sua vida.

Com relação à conceituação da teoria da atividade propriamente dita, ela procura explicar como os indivíduos se ajustam às mudanças relacionadas à idade. Ela é baseada em duas hipóteses: a primeira aponta que as pessoas mais velhas e ativas são mais satisfeitas e mais bem ajustadas do que aquelas que são passivas. Já a segunda hipótese estaria vinculada ao fato de que pessoas mais velhas podem vir a substituir perdas de papéis por novos, para manterem seu lugar na sociedade (HOOYMAN; KIYAK, 2002). Assim, à medida que as pessoas vão saindo do mercado de trabalho, ou mesmo que vão deixando de ocupar papéis sociais, as pessoas mais velhas buscariam atividades compensatórias àquelas anteriores. Tais atividades têm como finalidade trazer maior satisfação à vida das pessoas adultas maduras e idosas, tornando-as mais ativas.

A teoria da atividade, a partir da sua formulação, influenciou comportamentos de pessoas mais velhas e também contribuiu para o surgimento de políticas públicas nos anos 70, permitindo maior flexibilidade para o surgimento de movimentos sociais, centros de lazer e da educação não-formal para adultos maduros e idosos (SIQUEIRA, 2002; BEARON, 1996).

Atualmente, a teoria na sua forma restrita tem sido questionada pelos gerontologistas em função de defender um único estilo de vida como o ideal para as pessoas. E, embora tenha impulsionado movimentos para a promoção do bem-estar na velhice, ela possui limitações em diferentes aspectos. A primeira delas se refere ao uso indiscriminado do concei- 
to atividade. Como os estudos de Lemon, Bengtson e Peterson (1972) e Longino e Kart (1982) demonstraram, são principalmente as atividades informais com amigos que contribuem para uma maior satisfação de vida. Uma segunda restrição seria quanto ao grau de adesão na realização de atividades que preencham o tempo das pessoas aposentadas ou mesmo idosas. Em muitos casos, as pessoas investirão seus interesses conforme sua motivação, suas vivências passadas, ou mesmo de acordo com seu estilo de vida ou nível socioeconômico. Outras limitações da teoria estariam quando se enfoca a relação entre atividade e satisfação, não levando em consideração a escolha por um estilo de vida menos ativo, as condições de saúde, de bem-estar ou do status social e econômico (BEARON, 1996; HOOYMAN; KIYAK, 2002; SIQUEIRA, 2002).

A ênfase na ação, preconizada pela teoria, pode encobrir a diversidade de indivíduos do processo de envelhecimento, uma vez que nesta heterogeneidade podem existir pessoas que prefiram um envelhecimento menos ativo, e mesmo aquelas que não possuem condições de vida saudáveis para a realização de tarefas que preencham seu tempo ocioso. Um olhar mais analítico sobre esta teoria poderia revelar um pensamento reducionista, uma vez que há a "proposição de que o idoso controla as atividades e o cenário necessário ao desempenho de novas atividades". No entanto, existem fatores como o "Declínio físico e mental que podem impossibilitar a compensação de seus antigos papéis." (SIQUEIRA, 2002, p. 49).

Outro aspecto se refere ao enfoque no idoso ativo e no bem-estar que muitas vezes acaba por criar uma perspectiva de "antienvelhecimento" (SIQUEIRA, 2002, p. 49), relegando ao segundo plano a abordagem de assuntos como a morte, que dificilmente encontra espaço de debate nessa teoria.

Como última limitação, a teoria é por vezes mal entendida quando aplicada na prática com os idosos, pois pode levar à falsa impressão de ativismo. Isto é, na maioria das vezes, a teoria pode passar a idéia de que para se envelhecer bem é preciso que a pessoa esteja engajada constantemente em alguma atividade.

\section{Teoria do Desengajamento}

A teoria do desengajamento foi formulada por Cumming e Henry, no livro Growing Old (1961), baseada nos dados de uma pesquisa reali- 
zada com 279 moradores de Kansas City e cidades-satélites, com idades entre 50 e 90 anos e que eram física e financeiramente auto-suficientes. Essa teoria representa a primeira tentativa de forma compreensiva, explícita e multidisciplinar de explicar o processo de envelhecimento com base nas mudanças nas relações entre o indivíduo e a sociedade (MARSHALL, 1999). Ela tem como mérito ser a primeira a colocar em evidência aspectos sociopsicológicos da investigação gerontológica. A obra de Cumming e Henry (1961) é considerada "clássica", pois a partir desta teoria os debates e investigações gerontológicos aumentaram significativamente (LEHR; THOMAE, 2003).

A teoria do desengajamento questionou quase todos os pressupostos gerontológicos sobre os desejos das pessoas idosas em relação ao trabalho, ao afirmar que as pessoas idosas desejam reduzir seus contatos sociais, e que com isso se sentem mais felizes e contentes. A atividade continuada, um valor da meia idade, é questionada como um valor necessário para os idosos, pois isso leva em algum momento no processo do envelhecimento a um conflito entre a continuidade da atividade e da expansão, de um lado, e o enfrentamento subliminar com o final da vida, de outro lado. Cumming e Henry (1961) põem em dúvida a contribuição à satisfação das pessoas idosas ao "possuírem uma função" e "serem úteis" (LEHR; THOMAE, 2003).

Segundo Cumming e Henry (1961), a teoria do desengajamento na velhice é desenvolvida a partir do senso comum, segundo o qual pessoas idosas estão menos envolvidas na vida ao seu redor do que quando elas eram mais jovens. Nesta teoria, envelhecimento é um acontecimento mútuo e inevitável de retirada ou desengajamento, resultando em diminuição nas interações entre a pessoa que está envelhecendo e os membros que compõem seu sistema social.

Este processo pode ser iniciado tanto pelo indivíduo que está envelhecendo como pelo sistema social. Quando o processo de envelhecimento se der por completo, o equilíbrio que existia na meia idade entre o indivíduo e a sociedade dará lugar a um novo equilíbrio caracterizado por um certo distanciamento. por uma diminuição das relações sociais e por uma modificação no tipo de relacionamentos.

Em qualquer processo em que o indivíduo se torne menos ligado ao sistema social do qual ele é membro, devem ser observadas mudanças. Cumming e Henry (1961) formulam, então, três tipos de mudanças que 
devem orientar a pesquisa empírica:

a) primeiro: mudanças na quantidade de contatos sociais devem ser observáveis (número de pessoas, número de contatos, propósitos dos contatos);

b) segundo: devem-se encontrar também mudanças na qualidade dos contatos, no estilo ou padrão de interação entre os indivíduos e os outros membros do sistema, isso pode ser medido pela diminuição do envolvimento;

c) terceiro: devem-se observar mudanças na personalidade do indivíduo, causando diminuição no envolvimento com outros e aumentando sua preocupação com ele mesmo.

Apesar de o processo de desengajamento ser pensado como universal, Cumming e Henry (1961) apontam para um processo diferente entre homens e mulheres, porque o papel central que eles exercem na sociedade são diferentes, com regras de conduta específicas, com critérios de desempenho e qualidade definidos.

O papel dos homens é instrumental, é trabalhar fora, requer habilidades mecânicas ou conhecimentos técnicos e se distancia de casa. É aquele que traz as condições econômicas para a família, articulando-a com a sociedade através da sua profissão, devendo impedir que a mesma se desarticule por problemas financeiros e se encarregando de manter a família em um status social.

Já o papel da mulher está relacionado ao lado mais social (igreja, escola), ou seja, a tarefa primária é criar um ambiente livre de tensões e conhecer as normas e valores da sociedade. A tarefa de uma mulher, no que diz respeito à família, é primeiramente aquela de reduzir a tensão entre os membros, desenvolvida no curso da atividade instrumental sob as circunstâncias que exigem um controle considerável, e de reforçar os valores e normas da família, dessa forma mantendo a integridade e reforçando as normas que governam os objetivos da família.

O ponto de partida é a definição de desengajamento:

Desengajamento é um processo inevitável durante o qual muitas das relações entre uma pessoa e os outros membros da sociedade são rompidas e aquelas que permanecem são modificados qualitativamente. (DAMIANOPOULOS, 1961, p. 211, tradução Johannes Doll). 
No livro Growing Old: the process of disengagement, Damianopoulos (1961) resume as principais idéias da teoria do desengajamento em nove postulados:

a) postulado 1: embora os indivíduos sejam diferentes, a expectativa de morte é universal, e a perda das habilidades é provável. Por isso, um rompimento mútuo dos vínculos entre uma pessoa e os outros de uma sociedade acontecerá;

b) postulado 2: as interações sociais criam e reafirmam as normas presentes em uma sociedade. Por isso, um número reduzido de interações oferece, por um lado, uma maior liberdade aos idosos; por outro lado, reforça o desengajamento, pois os idosos não conseguem mais estabelecer novos vínculos por não encontrarem mais uma base fundo comum com outros. Desta forma, o desengajamento se torna um processo circular;

c) postulado 3: o papel principal dos homens na sociedade é instrumental, e o papel central das mulheres é sócio-emocional; o processo de desengajamento diferirá entre homens e mulheres;

d) postulado 4: o ciclo de vida do indivíduo é pontuado por mudanças do ego. Por exemplo: envelhecer é comumente associado à perda de conhecimento e habilidades; ao mesmo tempo, sucesso na sociedade industrializada é baseado em conhecimento e habilidades. A classificação etária é um mecanismo utilizado para garantir que um jovem está suficientemente pronto para assumir responsabilidades, e que o velho será aposentado antes da perda das habilidades;

e) postulado 5: quando ambos (indivíduo e sociedade) estão prontos para o desengajamento, isso acontecerá. Quando nenhum está pronto, o engajamento continua. Quando o indivíduo está pronto e a sociedade não está, uma disfunção entre expectativas do individuo e dos membros do sistema social acontece, mas usualmente o engajamento continua. Quando a sociedade está pronta e o indivíduo não, o resultado é usualmente o desengajamento. Isso significa que geralmente prevalece a posição da sociedade;

f) postulado 6: o abandono dos papéis principais da vida - o trabalho para, os homens; e o casamento e a família, para as mulheres - resultará numa dramática redução da vida social, levando a crises e perda da moral, a menos que outros papéis, apropriados para o estado de desengajamento, estejam disponíveis; 
g) postulado 7: se o indivíduo se torna, de repente, consciente da brevidade de sua vida e da escassez de tempo que lhe sobra, e se ele percebe a diminuição do seu espaço de vida, e se sua energia disponível está diminuindo, então ele está pronto para o desengajamento;

h) postulado 8: as reduções nas interações e a perda de papéis centrais resultam numa mudança na qualidade dos relacionamentos nos papéis restantes;

i) postulado 9: desengajamento é um conceito livre de cultura, mas a forma que assumirá será sempre marcada pela cultura. Na sociedade americana o desengajamento é mais difícil para homens do que para mulheres. Em sociedades chamadas clássicas, como a China, que é patriarcal e tradicional, e por isso valoriza a sabedoria, o papel do homem quase não muda com o envelhecimento, e em alguns casos eles tornam-se mais engajados do que eram antes da velhice. ${ }^{11}$

A teoria do desengajamento, principalmente pela sua posição polêmica em relação às práticas gerontológicas, teve profundo impacto no campo da Gerontologia. Desde seu lançamento, foi criticado, em relação à análise dos dados (LEHR; THOMAE, 2003) e a seus pressupostos (enfrentamento da morte mais fácil quando desengajado), mas principalmente em relação à suposta universalidade do desengajamento. A respeito disso, Neri (2005, p. 203) aponta que a teoria do desengajamento não levou em conta que a "velhice comporta vários tipos de experiência de afastamento dependentes de variáveis, como: classe social, profissão, renda, educação, status e envolvimento social, gênero e saúde física e psicológica”. O desengajamento pode ocorrer em algumas áreas da vida, mas não em todas.

Através das críticas, a teoria do desengajamento recebeu um grande número de modificações. Lehr e Thomae (2003), na sua revisão crítica da teoria, destacam algumas destas modificações e críticas que foram elaboradas desde o lançamento da teoria.

Três pesquisadores que também trabalharam na Kansas City Study, Havighurst, Neugarten e Tobin, mas que tiveram uma perspectiva diferente de Cumming e Henry (MARSHALL, 1999), diferenciam o processo de desengajamento. Por um lado, eles destacam os aspectos qualitativos. Nesta perspectiva, o envelhecimento seria menos marcado por uma diminuição quantitativa de contatos, mas por uma reestruturação qualitativa destes contatos e por um envolvimento interno diferente nos papéis exerci-

${ }^{11}$ Tradução livre, de forma resumida, dos nove postulados de Damianopoulos, 1961, p. 211-218. 
dos. Por outro lado, eles apontam para diferenças a partir da personalidade. Enquanto pessoas com comportamentos mais passivos ficariam mais contentes quando pudessem retirar-se das atividades exigidas delas, pessoas com personalidades mais ativas continuariam voltadas para engajamento e atividades. Finalmente, apontam para a possibilidade de um engajamento compensatório. Isso significa que pessoas podem diminuir suas atividades em uma área, por exemplo, na profissão, mas podem compensar isso através de um engajamento em outros setores, como na família ou em atividades voluntárias (LEHR; THOMAE, 2003).

Outras discussões focalizaram na possibilidade do desengajamento como um processo temporário. O "desengajamento transitório", que foi observado em uma pesquisa na Alemanha sobre trabalhadores metalúrgicos durante a fase da aposentadoria (LEHR, 2000, p. 60), aconteceria em certos momentos de vida marcados por crises ou por perda de papéis importantes, o que levaria a um desengajamento por um certo tempo. Com a crise elaborada, as pessoas retomariam seu nível de atividades.

Algumas pessoas mais idosas, especialmente em outras culturas, podem assumir novos papéis de prestígio e de poder. Do mesmo modo, nem todos em nossa cultura desengajam, como evidenciado pelo crescente número de pessoas mais velhas que permanecem empregadas, saudáveis, política e socialmente ativas. O envelhecimento bem sucedido é mais provável de ser conseguido pelas pessoas que permanecem engajadas na sociedade. A teoria do desengajamento também não esclarece a heterogeneidade entre os indivíduos, pois propõe solução para o dualismo pessoaambiente, afirmando que as demandas biológicas e sociais se assemelham na velhice, apresentando estilos de vida homogêneos. Outra questão seria supor que a retirada de pessoas mais velhas dos papéis úteis é necessariamente boa para a sociedade (LEHR; THOMAE, 2003).

Siqueira (2002), na sua revisão das teorias sociológicas, destaca que o desengajamento pode ser visto como um comportamento adaptativo. Dessa forma, propõe-se o próprio envelhecimento como um processo de desengajamento. A teoria enfatizaria o desengajamento do prisma da funcionalidade, mutualidade, inevitabilidade e universalidade do afastamento típico do envelhecimento.

O desengajamento é considerado funcional tanto para o indivíduo como para a sociedade, uma vez que, com o afastamento do idoso do mundo produtivo, possibilita à sociedade abrir espaço para os mais jovens e 
mais eficientes e, assim, manter a estabilidade social, enquanto dá ao idoso tempo para se preparar para o desengajamento total: a morte. Quanto à mutualidade, a teoria postula que a sociedade se afasta das pessoas idosas na mesma proporção em que essas pessoas se afastam da sociedade de modo mais ou menos voluntário. Em relação à inevitabilidade, o desengajamento é considerado como um processo natural e espontâneo, reforçando a idéia de que à medida que o indivíduo vai envelhecendo as interações sociais vão diminuindo e, por isso, é inevitável. Conforme a teoria, para se manter o equilíbrio da sociedade, todo o sistema precisa promover o desengajamento dos idosos. Dessa forma decorre a idéia de universalidade (SIQUEIRA, 2002; NERI, 2005).

A teoria do desengajamento possui fortes raízes no momento sócio-histórico em que foi elaborada. Isso fica evidente na análise dos papéis típicos de homens e mulheres (trabalho-família) o que remete à sociedade norte-americana dos anos 50 e 60. Este aspecto é destacado também por Atchley (1989), que aponta para a situação dos idosos, na década de 50, nos Estados Unidos, que era pior do que a da atualidade, tanto no que se refere à aceitação do indivíduo em relação à velhice quanto à opinião pública em relação às pessoas idosas. Diante da realidade da época, era muito mais difícil para as pessoas se adaptarem à velhice. Por isso o desengajamento foi para muitas pessoas uma resposta óbvia à situação que estavam vivendo.

\section{Teoria da Modernização}

No senso comum, pessoas idosas são resistentes à inovação e possuem uma certa desconfiança em relação às coisas técnicas e modernas. Um reflexo disso é que, no mundo moderno da tecnologia, as pessoas idosas não dispõem de grande prestígio. Em um mundo marcado pela mudança acelerada, o idoso ganha a conotação de antigo e ultrapassado. A teoria da modernização elabora suas reflexões exatamente a respeito desta idéia, do status e do prestígio da pessoa idosa nas sociedades modernas. Ao contrário das teorias anteriores, que abordam a relação entre bem-estar e atividade dos idosos na sociedade, a teoria da modernização trabalha com a imagem do idoso e com as representações que influenciam essa imagem.

O primeiro estudo antropológico dedicado especificamente às pessoas idosas é a obra The Role of the Aged in Primitive Society, publicado 
em 1945 por Leo Simmons. No estudo que utiliza dados de 71 sociedades não-industrializadas, ele analisa o status e o tratamento que idosos recebem nestas sociedades, a partir das variáveis ecologia, economia, contatos sociais, organização política e crenças religiosas. Segundo Fry (1999), não se encontra uma clara prova de um tratamento melhor dos idosos em sociedades menos complexas. Em vez disso, o estudo de Simmons (1945) demonstra uma complexidade e variabilidade das formas de tratamentos dos idosos.

Uma posição parecida a respeito do tratamento de pessoa idosa em diferentes sociedades é assumida por Simone de Beauvoir (1990), na sua obra La Vieillesse, publicada originalmente em 1970. Apesar de a autora acusar as sociedades contemporâneas de manter um silêncio sobre a situação escandalosa das pessoas idosas, ela mostra na sua análise que a negligência em relação aos idosos vem de longa data, que eles foram maltratados também em sociedades antigas e que o prestígio dependia muito mais da classe social do que da idade. A análise detalhada de Simone de Beauvoir (1990) desmonta a imagem nostálgica de uma época de ouro dos idosos nas sociedades antigas.

A questão da reputação social do idoso nas diferentes sociedades é retomada por Cowgill, que propõe em 1972, em uma publicação, junto com Holmes, a teoria da modernização, que relaciona, a partir de uma revisão de vários estudos sobre o papel do idoso nas determinadas sociedades, o processo de modernização da sociedade como um declínio no status dos idosos (Cowgill; Holmes, 1972). Em 1986, Cowgill amplia a base de dados sobre qual ele tece sua teoria e apresenta, agora de forma mais ampla e diferenciada, a teoria de modernização no livro Aging Around the World $^{12}$.

Antes de entrar nos detalhes da teoria da modernização, é necessário definir mais claramente este conceito. O próprio Cowgill discute diferentes propostas, para depois fornecer sua própria definição:

Modernização é a transformação de uma sociedade inteira de um estilo de vida dominantemente rural, baseado na força dos animais, com uma tecnologia limitada, com instituições pouco diferenciadas, pontos de vista e valores tradicionais e "paroquiais", em direção a um

${ }^{12}$ A apresentação da teoria da modernização baseia-se na obra de Cowgill, 1986. 
estilo de vida predominantemente urbana, baseado em fontes de energia sem recursos aos animais, uma tecnologia científica altamente desenvolvida, instituições altamente diferenciadas, interligadas com papéis individuais segmentados e com perspectivas cosmopolitas com ênfase em eficiência e progresso. (COWGILL, 1986, p.185-186, tradução Johannes Doll).

Nesta obra, Cowgill analisa estudos de cunho sociológico e antropológico sobre o papel de pessoas idosas em diferentes sociedades, para sustentar a teoria da modernização. Esta análise é estruturada a partir de áreas-chave em que o status de pessoas idosas pode modificar-se durante o processo de modernização: mudanças demográficas, os valores, as estruturas familiares, o sistema econômico, as estruturas políticas e os sistemas religiosos e educacionais.

$\mathrm{Na}$ discussão dos dados demográficos, Cowgill (1986) destaca a importância da transição demográfica no processo da modernização, marcada pela diminuição da mortalidade e pelo aumento da longevidade. Os resultados são sociedades envelhecidas com um grande número de pessoas idosas, com um número maior de mulheres, na maior parte viúvas, do que de homens e com poucas crianças e jovens. As sociedades mais ricas e desenvolvidas encontram-se hoje nesta situação, enquanto as sociedades jovens, com poucas pessoas idosas e muitas crianças, geralmente são mais pobres e com tecnologias menos desenvolvidas.

A respeito dos valores existentes em uma sociedade, Cowgill (1986) diferencia entre dois quadros possíveis. O primeiro quadro, favorável aos idosos, se refere às sociedades nas quais a família é valorizada, onde predomina a piedade dos filhos a respeito dos seus pais e onde a hierarquia representa um valor importante. A situação se torna menos favorável para o status do idoso nas sociedades que valorizam fortemente o trabalho, o individualismo, a igualdade e onde existe um culto à juventude. Cowgill destaca ainda que o primeiro grupo de valores se encontra mais em sociedades pré-industrializadas, enquanto o segundo grupo de valores está mais presente em sociedades modernas.

A família sempre foi uma referência social importante para as pessoas idosas, menciona Cowgill (1986, p. 55) e cita Leo Simmons (tradução Johannes Doll): "Durante a história humana, a família era o porto mais seguro para os idosos; exatamente lá, em casa e no círculo dos familiares, 
o idoso encontrou sempre a maior segurança nos anos finais da sua vida." (Simmons, 1945, p. 177). Porém, existem diferentes configurações familiares, e Cowgill (1986) vai demonstrando as variedades, em relação à distribuição do poder dentro da família, a respeito da linhagem de descendência, em relação à forma de casamento e a respeito da forma de morar. De fato, Cowgill (1986) encontra diferenças a respeito da estrutura familiar entre as sociedades, e aponta também que a tendência para a família nuclear nas sociedades modernas geralmente não corta os vínculos entre as gerações, pois normalmente os idosos, quando não moram juntos com os filhos, moram perto deles, o que possibilita maior autonomia, mantendo os contatos. Mesmo assim, nota-se uma certa perda de poder, pois especialmente nas famílias patriarcais, onde os membros mais velhos continuam no mesmo domicílio com os mais jovens, os idosos conseguem geralmente manter uma posição de maior poder. Apesar de todas as diferenças, Cowgill (1986) constata que as relações familiares constituem um fundamento importante da satisfação de vida dos idosos, tanto os contatos com as gerações mais novas, quanto as relações dos idosos com os membros da mesma geração, como irmãos e primos.

A quarta área que Cowgill (1986) analisa é o sistema econômico e os papéis econômicos dos idosos. Em sociedades pré-industriais, as pessoas idosas tendem a continuar suas atividades econômicas, mesmo se é possível notar uma certa mudança causada por uma diminuição das forças físicas. Somente nas sociedades industrializadas encontra-se um sistema de aposentadoria, baseado na idade cronológica. Trata-se de uma transferência do suporte dos idosos, que antes era da responsabilidade da família, para a esfera pública. Em quase todas as sociedades, as pessoas tentam preparar sua sobrevivência na velhice, e especialmente em sociedades estáveis rurais, elas o fazem através da aquisição ou controle da terra, o que garante para os mais idosos um poder sobre os mais jovens. Em relação ao desenvolvimento das atividades durante a vida inteira, Cowgill (1986) nota três padrões. No primeiro, existe uma expectativa de ascensão, chegando na velhice como uma pessoa reconhecida e respeitada, um padrão encontrado geralmente em sociedades pastoris e agrárias. O segundo padrão é da expectativa de uma continuidade durante o envelhecimento, mantendo suas principais atividades. Este padrão não é restrito a um determinado tipo de sociedade, é bastante freqüente e encontra-se até parcialmente em sociedades industrializadas. Agora, o terceiro padrão, de uma parada abrupta 
a partir de uma determinada idade, encontra-se somente nas sociedades industrializadas através da instituição da aposentadoria. Ainda a respeito das diferenças entre homens e mulheres, Cowgill (1986) nota em praticamente todas as sociedades diferenças em relação aos papéis e às atividades, mesmo se tendem a diminuir com a idade, aproximando os comportamentos de homens e mulheres na velhice. Outras diferenças fortes são observadas entre as classes sociais, mas nesta área, segundo Cowgill (1986), ainda faltam estudos mais específicos.

As pessoas idosas não exercem um papel importante somente na família. Em muitas sociedades, elas assumem também papéis políticos, como conselheiros, chefes de tribos etc. O poder dos idosos pode tornar-se tão forte, que já foi usada a expressão de "gerontocracia", onde o poder principal se encontra nas mãos de um grupo de pessoas idosas. A importância dos idosos nas sociedades, e com isso sua possibilidade de exercer poder político, se baseia principalmente no uso de mágica, na referência aos antecessores, no controle sobre propriedades valorizadas em uma determinada sociedade, em um acúmulo de obrigações recíprocas e no monopólio de informações importantes. Este sistema pode ser reforçado através de valores como respeito à hierarquia, piedade filial e da importância de uma linhagem de sangue. Estas constelações aparecem, principalmente, em sociedades pastoris e baseadas em agricultura, e tendem a diminuir em sociedades industriais modernas. Porém, o declínio do poder dos idosos parece bem menor no papel político do que nas funções econômicas. Também nos papéis políticos encontram-se grandes diferenças entre homens e mulheres, em praticamente todas as sociedades conhecidas: homens velhos exercem um papel político muito mais poderoso do que mulheres velhas.

Os últimos campos que Cowgill (1986) analisa são o da religião e o da educação. Em sociedades pré-industriais, estas áreas se misturam e são redutos de pessoas idosas. Elas possuem o conhecimento, a memória e a experiência para orientar os outros membros da sociedade, principalmente os mais jovens. Em culturas pré-escritas, as narrativas dos idosos em forma de histórias, lendas e mitos representam o fundo de conhecimento disponível, e cabe aos idosos iniciar os mais jovens na cultura e na sabedoria da sociedade. Esta função de transmissor de conhecimentos e cultura, que garante a valorização e o status das pessoas idosas, se perde com a possibilidade de registros que perpetuam o saber independentemente de pessoas concretas. Com a aceleração da mudança social, com a possibilidade de 
estocar conhecimentos na forma escrita ou digital, e com a profissionalização da educação (professores), os idosos perderam totalmente sua função de educadores nas sociedades modernas. Mais ainda: com o rápido acúmulo de informações e a inovação constante do saber, os conhecimentos dos idosos se tornaram sinônimo de antigo e ultrapassado.

Com este estudo abrangente, Cowgill vê confirmada, em linhas gerais, a teoria apresentada por ele e Holmes, em 1972 (Cowgill; Holmes, 1972). Neste trabalho, eles tinham listado 22 itens, relacionando velhice e modernização nas sociedades. No trabalho de 1986, Cowgill sustenta treze itens que utilizam a modernização como principal variável independente, enquanto os outros nove itens se referem a relações entre o status de idosos e características sociais que são aspectos subordinados à modernização, como mudança social, estabilidade de residência, alfabetização, urbanização etc, dos quais listamos:

1. O conceito de velhice é relativo em relação ao grau de modernização; uma pessoa é classificada como "velha" em uma idade cronológica mais jovem em uma sociedade primitiva do que em uma sociedade moderna.

2. Velhice é identificada a partir da idade cronológica principalmente em sociedades modernas; em outras sociedades, a entrada da velhice é mais vinculada a eventos como sucessão na posição do mais velho ou tornar-se avó.

3. Longevidade é direta e significativamente relacionada ao grau de modernização.

4. Sociedades modernas possuem uma população mais velha, o que significa uma proporção maior de pessoas idosas.

5. Sociedades modernas possuem uma proporção mais alta de mulheres e especialmente de viúvas.

6. Sociedades modernas possuem uma proporção maior de pessoas que chegam a ser avôs ou mesmo tataravôs.

7. O status de pessoas idosas é alto em sociedades primitivas e mais baixo e mais ambíguo em sociedades modernas.

8. Em sociedades primitivas, pessoas idosas tendem a 
ocupar posições de poder político e econômico, mas em sociedades modernas, este poder é possuído somente por poucos. [...]

16. Aposentadoria é uma invenção moderna; ela é encontrada principalmente em sociedades modernas de alta produtividade. [. . .]

18. Com a modernização, a responsabilidade de providenciar segurança econômica para idosos dependentes se transfere da família para o Estado.

19. A proporção de idosos que conseguem manter papéis de liderança diminui com a modernização.

20. Em sociedades primitivas, os papéis das viúvas tende de ser claramente definidos, mas as prescrições para o papel de viúva diminuem com a modernização; o papel da viúva em sociedades modernas tende a ser mais flexível e ambivalente. [...]

22. Afastamento (desengajamento) não é uma característica do idoso em sociedades primitivas ou agrárias, mas uma crescente tendência de afastamento (desengajamento) parece acompanhar a modernização." (COWGILL, 1986, p. 188-190, tradução Johannes Doll).

Em uma resposta às críticas proferidas contra a teoria da modernização, Cowgill aponta ainda que esta teoria não reforçaria uma idéia romântica de idade de ouro de pessoas idosas nos tempos anteriores, pois ela destaca a existência de poucas pessoas idosas antigamente, a pobreza de forma geral e o fato de possuir um status alto ou uma gerontocratia não significam, necessariamente, uma forma positiva de convívio.

Mas Cowgill (1986) aceita outro argumento, de que em sociedades antigas, baseadas na caça, o status das pessoas idosas também não seja alto. Em função disso, ele propõe uma reformulação da teoria da modernização, não como um processo linear, mas mais como uma forma de curva. Enquanto nas primeiras sociedades, cujo sustento se baseia em coletar e caçar, o status das pessoas idosas é baixo, a consideração dos idosos aumenta e alcança um topo em sociedades rurais baseadas em agricultura, pois a posse da terra é o instrumento principal no campo da economia, com que estes sustentam seu poder. Posteriormente, durante o processo de modernização, marcado pela diminuição da agricultura, pela urbanização e pelo aumento da família nuclear, o status das pessoas idosas decai fortemente. 


\section{Conclusões}

Olhando para as três teorias, percebe-se claramente que as histórias das duas primeiras - atividade e desengajamento - são fortemente entrelaçadas. Ambas as teorias se desenvolveram a partir do mesmo estudo - a Kansas City Study — iniciado por Havighurst, mas chegaram a resultados opostos. Na discussão científica, as duas se desenvolveram, porém de formas bem diferentes. Como Marshall (1999) demonstra, esta curiosidade se deve ao fato de que o grupo de pesquisa se dividiu em dois subgrupos com experiências diferentes em estudos gerontológicos e focos teóricos divergentes.

A teoria do desengajamento formulou uma posição contra uma teoria implícita (da atividade) do trabalho com pessoas idosas, que nega as especificidades da velhice, impondo aos idosos valores da meia-idade (CUMMING; HENRY, 1961). A partir da sua posição fundamental, que valoriza a velhice como uma fase própria de vida e que leva a sério a realidade da morte, posição esta detalhada nos 9 postulados principais da teoria (DAMIANOPOULOS, 1961), ela foi desenvolvida a partir de um único livro, o Growing Old de Cumming e Henry (1961). O interessante da teoria do desengajamento é que ela provocou muita crítica e, desta forma, instigou muitas pesquisas, mas os autores fizeram somente um esforço muito pequeno para defender sua teoria, através de um artigo de Henry in 1964 (LEHR, 2000). Para compreender o debate gerontológico apaixonado a respeito desta teoria, especialmente no $6^{\circ}$ Congresso Internacional de Gerontologia em 1963, devem-se considerar dois fatos. O primeiro é que a Gerontologia naquela época tentou desfazer as imagens quase exclusivamente negativas presentes nas sociedades industrializadas, destacando o potencial das pessoas idosas. Nesta situação, a teoria do desengajamento não era em nada "politicamente correta". O segundo elemento é que a teoria do desengajamento é genuinamente sociológica e foi desenvolvida a partir da perspectiva da teoria sociológica do Funcionalismo estrutural de Talcott Parsons (MIKL-HORKE, 2001), quem, aliás, escreveu o prefácio para Growing Old (CUMMIG; HENRY, 1961). Este olhar voltado para o funcionamento de uma sociedade como um sistema frente aos seus membros envelhecidos, algo original no trabalho de Cumming e Henry em 1961 (LYNOTT; LYNOTT, 1996), que enxerga o indivíduo como uma pecinha que pode entrar e sair do jogo. Um olhar de certa forma frio em relação 
às vidas, aos problemas e aos sofrimentos dos indivíduos era uma posição totalmente contrária à ação apaixonada da maioria dos gerontólogos, que lutaram para acrescentar "mais vida aos anos ganhos", como escreveu Frank (1946) na primeira edição da revista Journal of Gerontology.

Já a teoria da atividade tomou outro rumo. Inicialmente, vindo mais do trabalho prático com pessoas idosas, esta teoria tomou forma, exatamente, pela provocação da teoria do desengajamento. Deste modo, os autores da teoria do desengajamento também "inventaram" a teoria da atividade (MARSHALL, 1999), a qual eles chamaram de "teoria implícita" (CUMMING; HENRY, 1961, p. 16). Como Lehr (2000) menciona, foi exatamente esta controvérsia que iniciou um grande estudo internacional comparativo cujos resultados demonstraram, apesar de diferenças nacionais e diferenças na execução de papéis, como profissional, pai, avô, parceiro etc., uma alta correlação entre atividade e satisfação de vida para as pessoas idosas, sustentando, assim, mais a teoria da atividade. Como teoria, ela não foi formulada de forma clara e determinada; às vezes, é até difícil de vincular a teoria da atividade a certos pesquisadores ou certas publicações. Ela se constituiu através de vários estudos e contribuições de diferentes autores, sem que um destes pudesse assumir a exclusiva paternidade desta teoria. Apesar de certas críticas, ela continua bastante presente e, especialmente no discurso prático gerontológico, está presente mais forte do que nunca. Ainda a respeito da relação entre a teoria da atividade e a do desengajamento, cabe mencionar as análises de Maddox e Eisdorfer ${ }^{13}$, relatados por Lehr (2000). Em uma análise dos dados da Kansas City Study, bem como dos dados da Duke-Longitudinal-Study, Maddox demonstra as relações entre atividades e satisfação. Os resultados desta análise mostram que $26-30 \%$ das pessoas se comportam segundo a teoria do desengajamento (baixa atividade — alta satisfação; alta atividade — baixa satisfação), enquanto $70-74 \%$ se comportariam segundo a teoria da atividade (baixa atividade - baixa satisfação; alta atividade — alta satisfação).

Enquanto as duas primeiras teorias focalizam mais no comportamento das pessoas idosas, na sua inserção na sociedade e no seu bemestar, a teoria da modernização trabalha com a imagem e o status social dos idosos nas diferentes sociedades. Também é interessante observar o desenvolvimento e a diferenciação desta teoria. Os primeiros passos da

${ }^{13}$ MADDOX, G.L.; EISDORFER, C. Zusammenhänge Zwischen Aktivität und Stimmung Bei Älteren Menschen. In: THOMAE, Hans; LEHR, Ursula (Orgs.). Altern: probleme und tatsachen. Frankfurt: Akadem. Verlagsgesellschaft, 1963. P. 235-252. Apud LEHR, 2000, p. 265.

Estud. interdiscip. envelhec., Porto Alegre, v. 12, p. 7-33, 2007. 
teoria são uma análise do papel e do status da pessoa idosa em sociedades primitivas de Simmons, em 1945 (HOOYMAN; KIYAK, 2002), uma perspectiva que se aproxima a um certo senso comum nostálgico, segundo o qual as pessoas idosas receberam antigamente uma atenção e um respeito maior, apesar de o estudo de Simmons apontar também para uma grande diversidade do status e tratamento das pessoas idosas. Simone de Beauvoir (1990) já demonstra que os idosos não eram tão bem tratados em todas as sociedades antigas. Mesmo assim, Cowgill e Holmes (1972) chegaram a propor uma relação direta entre o status da pessoa idosa e o grau de modernização da sociedade. A partir de uma análise mais detalhada de um número maior de estudos, Cowgill confirma no seu livro em 1986, por um lado, o declínio do status dos idosos nas sociedades modernas, por outro lado, diferencia a tese central da teoria, dependendo das atividades produtivas em determinadas sociedades. Em sociedades de caçadores, o status do velho é baixo, pois ele não consegue, a partir de certa idade, acompanhar a caça. Nas sociedades baseadas na agricultura, onde importa a posse da terra, o idoso consegue melhorar seu status, que começa declinar de novo com o processo da modernização, principalmente com a aceleração da inovação tecnológica. Cowgill (1986) também demonstra, que o status pode desenvolver-se de forma diferente em setores diferentes, como na política, na economia, na educação ou na religião. A discussão atual a respeito da teoria da modernização restringe seu valor explicativo e a aceita somente na sua forma fraca ${ }^{14}$, que quer dizer, em uma perspectiva diferenciada ${ }^{15}$.

As teorias apresentadas fazem parte de um grupo de "grandes teorias", as quais buscam explicar, de forma geral, a relação entre pessoas idosas, envelhecimento e sociedade. Os estudos e as pesquisas demonstraram que este tipo de teoria fica, em muitos casos, universal demais, levando a formas de explicação pouco precisas. Por isso, as gerações de teorias sociológicas posteriores restringiram-se a temáticas mais específicas (TEWS, 1971). Mas o conhecimento das teorias aqui apresentadas continua sendo importante. Por um lado, elas continuam sendo citadas em pesquisas e estudos atuais sobre o envelhecimento, por isso é altamente necessário para os estudiosos da gerontologia ter conhecimentos detalhados sobre elas. Por outro lado, elas estão presentes nas discussões atuais, geralmente de forma velada. Quando se discute a aposentadoria e o papel

\footnotetext{
${ }^{14} \mathrm{Na}$ discussão sobre o valor explicativo de uma teoria pode-se diferenciar entre "teorias fortes" que possuem um alto valor explicativo, e "teorias fracas", cujo valor explicativo é mais restrito.

${ }^{15}$ Veja, por exemplo, Aboderin, 2004.
} 
da pessoa idosa no mercado de trabalho, a teoria do desengajamento continua influenciando as posições e decisões no campo dos recursos humanos. A teoria da atividade está presente no discurso gerontológico e no trabalho prático com pessoas idosas. E em relação às mudanças rápidas da tecnologia e ao uso de recursos da informática por pessoas idosas, a teoria da modernização continua com seu valor explicativo.

Gostaríamos de concluir a revisão das teorias da atividade, do desengajamento e da modernização com dois apontamentos que Wahl e Heyl (2004) fazem sobre a importância das teorias. Em primeiro lugar, os autores lembram da imagem de Sir Karl Popper a respeito das teorias: teorias são as redes que lançamos para captar a realidade. E o segundo apontamento destaca os objetivos das teorias e pesquisas gerontológicas, pois elas devem servir para oferecer a base para uma descrição, uma explicação e um prognóstico dos processos de envelhecimento para, com isso, ter fundamentos para uma intervenção baseada em evidências.

\title{
ACTIVITY, DISENGAGEMENT, MODERNIZATION: classic so- ciological theories about aging
}

\begin{abstract}
Gerontology is a wide, interdisciplinary field. Besides the psychological theories, it was mainly the big sociological theories of the 1940s to 1980 s that inspired the international gerontological research. Those theories are historical, but they continue to influence research and practical work with elderly until now. This article presents and discusses the development of three sociological theories of aging: the activity theory, the disengagement theory and the modernization theory.

Keywords: Aging. Theories of Aging. Gerontology.
\end{abstract}

\section{REFERÊNCIAS}

ABODERIN, Isabella. Modernisation and Ageing Theory Revisited: current explanations of recent developing world and historical western shifts in material family support for older people. Ageing and Society, New York, v. 24, p. 29-50, 2004. 
ACHENBAUM, W. Andrew. Crossing Frontiers: gerontology emerges as a science. Cambridge: Cambridge University, 1995.

ATCHLEY, Robert C. A Continuity Theory of Normal Aging. The Gerontologist, Washington, DC, v. 29, n. 2, p. 183-190, 1989.

BEARON, Lucille B. Sucessful Aging: what does the "good life" look like? Concepts in Gerontology, North Carolina, v. 1, n. 3, Summer, 1996. Disponível em: <http://www.ncsu.edu/ffci/publications/1996/v1-n3-1996-summer/ successful-aging.php>. Acesso em: 27 mar. 2007.

BEAUVOIR, Simone de. A Velhice. Rio de Janeiro: Nova Fronteira, 1990.

BENGTSON, Vern L.; RICE, Cara J.; JOHNSON, Malcoln L. Are Theories of Aging Important? models and explanations in Gerontology at the turn of the century. In: BENGTSON, Vern L.; SCHAIE, Warner (Org.). Handbook of Theories of Aging. New York: Springer, 1999. P. 3-20.

COWGILL, Donald O.; HOLMES, Lowell D. (Org.). Aging and Modernization. New York: Appleton Century Crofts, 1972.

COWGILL, Donald O. Aging Around the World. Belmont: Wadsworth, 1986.

CUMMING, Elaine; HENRY, William E. Growing Old: the process of disengagement. New York: Basic Books, 1961.

DAMIANOPOULOS, Ernst. A Formal Treatment of Disengagement Theory. In: CUMMING, Elaine; HENRY, William E. Growing Old: the process of disengagement. New York: Basic Books, 1961. P. 210-218.

DEBERT, Guita Grin. A Reinvenção da Velhice: socialização e processos de reprivatização do envelhecimento. São Paulo: Edusp, 1999.

DOLL, Johannes. O Campo Interdisciplinar da Gerontologia. In: PY, Ligia et al. (Org.). Tempo de Envelhecer. 2. ed. Holambra: Setembro, 2006. P. 77-96. 
ERIKSON, Erik. O Ciclo de Vida Completo. Porto Alegre: Artes Médicas, 1998.

FRANK, Lawrence K. Gerontology. Journal of Gerontology, Washington, DC, v.1, n. 1, p. 7, 1946.

FRY, Christine L. Anthropological Theories of Age and Aging. In: BENGTSON, Vern.L.; SCHAIE, K. Warner (Org.). Handbook of Theories of Aging. New York: Springer, 1999. P. 271-286.

GROISMAN, Daniel. A Velhice: entre o normal e o patológico. História, Ciências, Saúde Manguinhos, Rio de Janeiro, v. 9, n. 1, p. 61-78, jan./abr. 2002.

HAVIGHURST, Robert J. Successful Aging. The Gerontologist, Washington, DC, v.1, n.1, p. 8-13, 1961.

HAVIGHURST, Robert J. Personality and Patterns of Aging. The Gerontology, Washington, DC, v. 8, p. 20-23, 1968.

HOOYMAN, Nancy; KIYAK, Asuman. Social Gerontology: a multidisciplinary perspective. 6th ed. Boston: Allyn and Bacon, 2002.

KNAPP, Martin. The Activity Theory of Aging: an examination in the English context. The Gerontologist, Washington, DC, v.17, n. 6, p. 553-559, 1977.

LEHR, Ursula. Psychologie des Alterns. 9. Aufl. Wiebelsheim: Quelle und Meyer, 2000 .

LEHR, Ursula; THOMAE, Hans. Psicología de la Senectud: proceso y aprendizaje del envejerimento. Barcelona: Heder, 2003.

LEMON, Bruce; BENGTSON, Vern; PETERSON, James. An Exploration of the Activity Theory of Aging: activity types and life satisfaction among in-movers to a retirement community. Journal of Gerontology, Washington, DC, v. 27, n. 4, p. 511-523, 1972.

LONGINO, Charles; KART, Cary. Explicating Activity Theory: a formal replication. Journal of Gerontology, Washington, DC, v. 37, n.6, p.713-722, 1982.

Estud. interdiscip. envelhec., Porto Alegre, v. 12, p. 7-33, 2007. 
LYNOTT, Robert J.; LYNOTT, Patricia Passuth. Tracing the Course of Theoretical Development in the Sociology of Aging. The Gerontologist, Washington, DC, v. 36, n. 6, p. 749-760, 1996.

MARSHALL, Victor W. Analyzing Social Theories of Aging. In: BENGTSON, Vern L.; SCHAIE, K. Warner (Org.). Handbook of Theories of Aging. New York: Springer, 1999. P. 434-455.

MCCLELLAND, Kent A. Self. Conception and Life Satisfaction: integrating aged subculture and activity theory. Journal of Gerontology, Washington, DC, v. 37, n. 6, p. $723-732,1982$.

MIKL-HORKE, Gertraude. Soziologie: historischer Kontext und soziologische Theorieentwürfe. 5. aufl. Oldenbourg: München Wien: 2001.

MOODY, Harry R. Philosophical Presuppositions of Education for Old Age. Educational Gerontology, Bristol, v.1, n.1, p. 1-16, 1976.

NERI, Anita Liberalesso. Palavras-Chave em Gerontologia. 2. ed. Campinas: Alínea, 2005.

NERI, Anita Liberalesso. Atitudes em Relação à Velhice: questões científicas e políticas. In: FREITAS, Elisabete Viana et al. (Org.). Tratado de Geriatria e Gerontologia. 2. ed. Rio de Janeiro: Guanabara Koogan, 2006. P. 1316-1323.

POPPER, Karl. A Lógica da Pesquisa Científica. São Paulo: Cultrix, 1974.

PRADO, Shirley Donizete; SAYD, Jane Dutra. A Pesquisa sobre Envelhecimento Humano no Brasil: grupos e linhas de pesquisa. Ciência e Saúde Coletiva, Rio de Janeiro, v.9, n.1, p.57-68, 2004.

PRADO, Shirley Donizete; SAYD, Jane Dutra. A Gerontologia como Campo do Conhecimento Científico: conceito, interesses e projeto político. Ciência e Saúde Coletiva, Rio de Janeiro, v. 11, n. 2, p. 491-501, 2006. 
SIMMONS, Leo W. The Role of the Aged in Primitive Society. New Haven: Conn, 1945.

SIQUEIRA, Maria Eliane Catunda. Teorias Sociológicas do Envelhecimento. In: NERI, Anita Liberalesso. Desenvolvimento e Envelhecimento: perspectivas biológicas, psicológicas e sociológicas. Campinas: Papirus, 2001.

SIQUEIRA, Maria Eliane Catunda. Teorias Sociológicas do Envelhecimento. In: FREITAS, Elizabete Viana et al. (Org.). Tratado de Geriatria e Gerontologia. Rio de Janeiro: Guanabara Koogan, 2002. P. 47-57.

SCHROOTS, Johannes. Theoretical Developments in the Psychology of Aging. The Gerontologist, Washington, DC, v. 36, n. 6, p. 742-748, 1996.

TEWS, Hans Peter. Soziologie des Alterns. Heidelberg: Quelle und Meyer, 1971.

WAHL, Hans-Werner; HEYL, Vera. Gerontologie: Einführung und Geschichte. Stuttgart: Kohlhammer, 2004.

Recebido em: 13/06/2007

$1^{a}$ revisão: 21/09/2007

Aceite final: 31/10/2007 